\title{
COMMENTARY
}

\section{Amyloid imaging in prodromal Alzheimer's disease}

\author{
Rik Ossenkoppele ${ }^{1,2 *}$, Bart NM van Berckel ${ }^{2}$ and Niels D Prins
}

\begin{abstract}
Patients with mild cognitive impairment are at an increased risk of progression to Alzheimer's disease. However, not all patients with mild cognitive impairment progress, and it is difficult to accurately identify those patients who are in the prodromal stage of Alzheimer's disease. In a recent paper, Koivunen and colleagues report that Pittsburgh compound-B, an amyloid-beta positron emission tomography ligand, predicts the progression of patients with mild cognitive impairment to Alzheimer's disease. Of 29 subjects with mild cognitive impairment, 21 (72\%) had a positive Pittsburgh compound-B positron emission tomography baseline scan. In their study, 15 of these 21 (71\%) patients progressed to Alzheimer's disease, whilst only 1 out of 8 (12.5\%) Pittsburgh compoundB-negative patients with mild cognitive impairment did so. Moreover, in these mild cognitive impairment patients, the overall amyloid burden increased approximately $2.5 \%$ during the follow-up period. This is consistent with other longitudinal amyloid imaging studies that found a similar increase in amyloid deposition over time in patients with mild cognitive impairment. These studies together challenge current theories that propose a flattening of the increase of brain amyloid deposition already in the preclinical stage of Alzheimer's disease. These findings may have important implications for the design of future clinical trials aimed at preventing progression to Alzheimer's disease by lowering the brain amyloid-beta burden in patients with mild cognitive impairment.
\end{abstract}

\section{Introduction}

Mild cognitive impairment (MCI) is considered a transitional stage between normal aging and dementia, in particular Alzheimer's disease (AD) [1]. The rate of conversion from MCI to $\mathrm{AD}$ is approximately $15 \%$ per year [2].

\footnotetext{
*Correspondence: r.ossenkoppele@vumc.nl

'Department of Neurology and Alzheimer Center, VU University Medical Center, Amsterdam, 1007 MB Amsterdam, the Netherlands
}

Full list of author information is available at the end of the article
However, a substantial number of MCI patients have cognitive complaints caused by other conditions, such as depression, stress, or sleeping disorders. It is important, therefore, for clinicians to identify individuals who are in the prodromal stage of $\mathrm{AD}$, in particular because these patients may be a target for future disease-modifying treatments. Advanced neuroimaging techniques may improve diagnostic accuracy in this patient group. The positron emission tomography (PET) ligand ${ }^{11} \mathrm{C}$ labeled Pittsburgh compound-B $\left(\left[{ }^{11} \mathrm{C}\right] \mathrm{PIB}\right)[3]$ detects fibrillary amyloid-beta $(\mathrm{A} \beta)$ in vivo, and may be used for this purpose. $\left[{ }^{11} \mathrm{C}\right] \mathrm{PIB}$ PET discriminates well between $\mathrm{AD}$ and controls [3,4] and between $\mathrm{AD}$ and other types of dementia [5], with the exception of dementia with Lewy bodies [6]. In patients with MCI, little is known about the predictive value of $\left[{ }^{11} \mathrm{C}\right] \mathrm{PIB}$ PET for progression to $\mathrm{AD}$, or about temporal changes in $\left[{ }^{11} \mathrm{C}\right] \mathrm{PIB}$ binding.

Recently, Koivunen and colleagues [7] reported the results of a prospective 2-year follow-up study in which they assessed the predictive value of $\left[{ }^{11} \mathrm{C}\right] \mathrm{PIB}$ PET for progression to $\mathrm{AD}$ as well as the temporal changes in amyloid deposition in MCI patients. In the present commentary, we discuss the findings of this study and its potential implications for future clinical trials with disease-modifying agents in prodromal AD.

\section{Identifying prodromal AD with [ $\left.{ }^{11} \mathrm{C}\right] \mathrm{PIB}$ PET}

Koivunen and colleagues [7] performed amyloid imaging with $\left[{ }^{11} \mathrm{C}\right]$ PIB PET at baseline and after 2 years of followup in a sample of $29 \mathrm{MCI}$ patients. They divided MCI patients into converters and non-converters, based on clinical diagnosis at follow-up. At baseline, MCI converters had substantially higher mean $\left[{ }^{11} \mathrm{C}\right] \mathrm{PIB}$ levels compared to MCI non-converters in the posterior cingulate, lateral frontal and temporal cortices and in putamen and caudate nucleus. After classifying $\left[{ }^{11} \mathrm{C}\right]$ PIB PET scans into either positive or negative, using a cut-off point of 1.5 standardized uptake value ratio (SUVr), 21 of 29 (72\%) subjects with MCI had a positive $\left[{ }^{11} \mathrm{C}\right] \mathrm{PIB}$ PET scan. In their study, 15 of the $21(71 \%)\left[{ }^{11} \mathrm{C}\right]$ PIB-positive MCI patients progressed to $\mathrm{AD}$ while only 1 out of 8 (12.5\%) $\left[{ }^{11} \mathrm{C}\right] \mathrm{PIB}$-negative MCI patients did so. These results are in accordance with several previous studies $[8,9]$ and indicate that $\left[{ }^{11} \mathrm{C}\right] \mathrm{PIB}$ PET predicts progression to $\mathrm{AD}$ in $\mathrm{MCI}$ patients. 


\section{Temporal changes in amyloid burden in $\mathrm{MCl}$}

Recently, Jack and colleagues [10] proposed a hypothetical model that positioned established and novel biomarkers in the continuum of AD. This model elaborates on the amyloid-cascade hypothesis [11], which states that accumulation of $A \beta$ initiates a cascade of neuropathological events, such as the formation of neurofibrillary tangles and neuroinflammation. This may in turn lead to neurodegeneration that presumably is followed by cognitive deterioration and finally results in dementia. Accumulation of $A \beta$ is thought to set in decades before the first cognitive complaints arise, starts to accelerate already in the preclinical stage of $\mathrm{AD}$, and reaches a relative plateau at the time symptoms emerge [12].

In the study by Koivunen and colleagues, the overall amyloid burden in MCI patients increased approximately $2.5 \%$ in 2 years. This increase was most prominent for those patients who did not convert to AD. However, the overall increase in amyloid deposition was only modest, whilst hippocampal volumes decreased more strongly. This is in line with the idea that $A \beta$ starts off the cascade and may uncouple at a later time point from neurodegenerative processes. Previous studies that related the presence of amyloid plaques with the course of brain atrophy [13] and glucose hypometabolism [14] also found this dissociation between amyloid deposition and structural and functional changes. The findings of Koivunen and colleagues suggest that the time span between deposition of amyloid and actual neurodegeneration may perhaps be shorter than previously assumed, given the dynamic $\mathrm{A} \beta$ changes in MCI patients in this study.

The finding of increased amyloid burden over time in MCI patients is consistent with other recent longitudinal amyloid imaging studies. Villemagne and colleagues [15] reported that $65 \mathrm{MCI}$ patients had a mean increase in $\left.{ }^{[11} \mathrm{C}\right] \mathrm{PIB}$ retention of $2.1 \%$ over a 20 -month follow-up period (annual increase of $1.3 \%$ ). A study by Jack and colleagues [16] showed an annual increase of $1.7 \%$ in 32 MCI patients. Moreover, in an unpublished study from our group in $12 \mathrm{MCI}$ patients, $\left[{ }^{11} \mathrm{C}\right] \mathrm{PIB}$ binding increased by $5.0 \%$ over a 30 -month period (annual increase $2 \%$ ). These results are in accordance with the $2.5 \%$ increase over 24 months (annual increase 1.25\%) reported by Koivunen and colleagues. In all these longitudinal studies, the increased amyloid burden was primarily driven by $\mathrm{MCI}$ patients that displayed high $\left[{ }^{11} \mathrm{C}\right] \mathrm{PIB}$ retention at baseline. Taken together, amyloid deposition seems to increase in both MCI converters and nonconverters, thereby challenging the theory that amyloid plaque load is stable in the prodromal stage of AD.

A limitation of the study by Koivunen and colleagues, especially given its longitudinal design, is the use of SUVr, which overestimates $\left[{ }^{11} \mathrm{C}\right] \mathrm{PIB}$ binding in comparison with fully quantitative kinetic models [17]. Furthermore, SUVr does not correct for factors that are inherently associated with disease progression, such as heterogeneous flow effects in the region of interest compared to the reference region. We therefore argue that quantitative modeling, and thus dynamic PET scanning, is essential for longitudinal amyloid imaging studies.

\section{Amyloid imaging in clinical trials}

The finding that $\left[{ }^{11} \mathrm{C}\right] \mathrm{PIB}$ PET can help identify prodromal AD patients and that most MCI patients show an increased amyloid burden over time may have implications for the design of future clinical trials. First of all, amyloid imaging may be used as an enrichment strategy by enabling the selection of subjects at risk for $\mathrm{AD}$, in order to administer disease-modifying agents to the right patients. Secondly, A $\beta$ PET ligands may be used as a secondary outcome measure to provide biological insight into cognitive primary outcome measures. Finally, amyloid imaging can be applied as a surrogate outcome measure to test whether anti-amyloid therapies are efficacious by measuring the amount of fibrillary $A \beta$ prior to and after the time window of the intervention. In this respect one should note that patients with prodromal AD may still show an increase in amyloid plaque formation, instead of the previously assumed plateau due to an equilibrium between production and clearance of $A \beta$. This will affect power calculations for such trials. Current development of several fluor-18-labeled amyloid PET tracers (which have a longer half-life time compared to carbon-11) will further increase the availability and applicability of amyloid imaging in both clinical practice and for scientific purposes.

\section{Conclusion}

Koivunen and colleagues showed that amyloid imaging may be used to predict clinical progression to AD in patients with MCI and that, contrary to current hypothetical biomarker models, amyloid deposition increases over time in patients with MCI. These findings are relevant for the design of future clinical trials aimed at the prevention of progression to $\mathrm{AD}$ by lowering the $\mathrm{A} \beta$ burden in the brains of patients with MCI.

\section{Abbreviations}

$\left[{ }^{11} \mathrm{C}\right] \mathrm{PIB},{ }^{11} \mathrm{C}$ labeled Pittsburgh compound-B; A 3 , amyloid-beta; $A D$, Alzheimer's disease; $\mathrm{MCl}$, mild cognitive impairment; $\mathrm{PET}$, positron emission tomography; SUVr, standardized uptake value ratio.

\section{Competing interests}

The authors declare that they have no competing interests.

\section{Author details}

'Department of Neurology and Alzheimer Center, VU University Medical

Center, Amsterdam, 1007 MB Amsterdam, the Netherlands. ${ }^{2}$ Department of Nuclear Medicine and PET Research, VU University Medical Center Amsterdam, 1007 MB Amsterdam, the Netherlands.

Published: 19 September 2011 


\section{References}

1. Petersen RC, Smith GE, Waring SC, Ivnik RJ, Tangalos EG, Kokmen E: Mild cognitive impairment: clinical characterization and outcome. Arch Neurol 1999, 56:303-308.

2. DeCarli C: Mild cognitive impairment: prevelance, prognosis, aetiology, and treatment. Lancet Neurol 2003, 2:15-21.

3. Klunk WE, Engler H, Nordberg A, Wang Y, Blomqvist G, Holt DP, Bergström M Savitcheva I, Huang GF, Estrada S, Ausén B, Debnath ML, Barletta J, Price JC, Sandell J, Lopresti BJ, Wall A, Koivisto P, Antoni G, Mathis CA, Långström B: Imaging brain amyloid in Alzheimer's disease with Pittsburgh compoundB. Ann Neurol 2004, 55:306-319.

4. Tolboom N, Yaqub M, van der Flier WM, Boellaard R, Luurtsema G, Windhorst $A D$, Barkhof F, Scheltens P, Lammertsma AA, van Berckel BNM: Detection of Alzheimer pathology in vivo using both 11C-PIB and 18F-FDDNP PET. J Nucl Med 2009, 50:191-197.

5. Rabinovici GD, Furst AJ, O'Neil JP, Racine CA, Mormino EC, Baker SL, Chetty S, Patel P, Pagliaro TA, Klunk WE, Mathis CA, Rosen HJ, Miller BL, Jagust WJ: 11C-PIB PET imaging in Alzheimer disease and frontotemporal lobar degeneration. Neurology 2007, 68:1205-1212.

6. Gomperts SN, Rentz DM, Moran E, Becker JA, Locascio JJ, Klunk WE, Mathis CA, Elmaleh DR, Shoup T, Fischman AJ, Hyman BT, Growdon JH, Johnson KA: Imaging amyloid deposition in Lewy body diseases. Neurology 2008 , 71:903-910.

7. Koivunen J, Scheinin M, Virta JR, Aalto S, Vahlberg T, Nagren K, Helin S, Parkkola R, Viitanen M, Rinne JO: Amyloid PET imaging in patients with mild cognitive impairment: a 2-year follow-up study. Neurology 2011, 76:1085-1090.

8. Forsberg $A$, Engler $H$, Almkvist O, Blomquist $G$, Hagman Gr, Wall A, Ringheim A, Longstrom B, Nordberg A: PET imaging of amyloid deposition in patients with mild cognitive impairment. Neurobiol Aging 2008, 29:1456-1465.

9. Okello A, Koivunen J, Edison P, Archer HA, Turkheimer FE, Någren K, Bullock R, Walker Z, Kennedy A, Fox NC, Rossor MN, Rinne JO, Brooks DJ: Conversion of amyloid positive and negative $\mathrm{MCl}$ to AD over 3 years: An 11C-PIB PET study. Neurology 2009, 73:754-760.
10. Jack CR Jr, Knopman DS, Jagust WJ, Shaw LM, Aisen PS, Weiner MW, Petersen RC, Trojanowski JQ: Hypothetical model of dynamic biomarkers of the Alzheimer's pathological cascade. Lancet Neurol 2010, 9:119-128.

11. Hardy JA, Selkoe DJ: The amyloid hypothesis of Alzheimer's disease: progress and problems on the road to therapeutics. Science 2002, 197:353-356.

12. Engler H, Forsberg A, Almkvist O, Blomquist G, Larsson E, Savitcheva I, Wall A, Ringheim A, Langstrom B, Nordberg A: Two-year follow-up of amyloid deposition in patients with Alzheimer's disease. Brain 2006, 129:2856-2866.

13. Tosun D, Schuff N, Mathis Chester A., Jagust W.J., Weiner MW, Alzheimer's Disease Neuroimaging Initiative: Spatial patterns of brain amyloid-beta burden and atrophy rate associations in mild cognitive impairment. Brain 2011, 134:1077-1088.

14. Förster S, Grimmer T, Miederer I, Henriksen G, Yousefi BH, Graner P, Wester HJ, Förstl H, Kurz A, Dickerson BC, Bartenstein P, Drzezga A: Regional expansion of hypometabolism in Alzheimer's disease follows amyloid deposition with temporal delay. Biol Psychiatry 2011 [Epub ahead of print].

15. Villemagne VL, Pike K, Chetelat G, Ellis KA, Mulligan R, Bourgeat P, Ackerman U, Jones G, Szoeke C, Salvado O, Martins R, O'Keefe G, Mathis CA, KlunkWE, Ames $D$, Masters $C L$, Rowe CC: Longitudinal assessment of $A \beta$ and cognition in aging and Alzheimer disease. Ann Neurol 2011, 69:181-192.

16. Jack CR Jr, Lowe VJ, Weigand SD, Wiste HJ, Senjem ML, Knopman DS, Shiung MM, Gunter JL, Boeve BF, Kemp BJ, Weiner M, Petersen RC; Alzheimer's Disease Neuroimaging Initiative: Serial PIB and MRI in normal, mild cognitive impairment and Alzheimer's disease: implications for sequence of pathological events in Alzheimer's disease. Brain 2009, 132:1355-1365.

17. Yaqub M, Tolboom N, Boellaard $R$, van Berckel BNM, van Tilburg EW, Luurtsema G, Scheltens P, Lammertsma AA: Simplified parametric methods for [11C]PIB studies. Neurolmage 2008, 42:76-86.

doi:10.1186/alzrt88

Cite this article as: Ossenkoppele $\mathrm{R}$, et al:: Amyloid imaging in prodromal Alzheimer's disease. Alzheimer's Research \& Therapy 2011, 3:26. 